\title{
Correction to: 68Ga-PSMA PET/CT tumour intensity pre-operatively predicts adverse pathological outcomes and progression-free survival in localised prostate cancer
}

\author{
Matthew J. Roberts ${ }^{1,2,3,4}$ (D) Andrew Morton ${ }^{4}$ (D) Peter Donato ${ }^{1,4}$ (D) Samuel Kyle S,5 $^{4}$ David A. Pattison ${ }^{4,5}$ (D) \\ Paul Thomas $^{4,5}$ (D) - Geoff Coughlin ${ }^{1} \cdot$ Rachel Esler $^{1}$ (D) - Nigel Dunglison ${ }^{1} \cdot$ Robert A. Gardiner $^{1,2,6,7}$ (D) \\ Suhail A. Doi ${ }^{8}$ (D) $\cdot$ Louise Emmett ${ }^{9,10}$ (D) - John Yaxley ${ }^{1,4}$ \\ Published online: 12 September 2020 \\ (C) Springer-Verlag GmbH Germany, part of Springer Nature 2020
}

\section{Correction to: European Journal of Nuclear Medicine and Molecular Imaging https://doi.org/10.1007/s00259-020-04944-2}

Figure $2 b$ is incorrect in the original paper, the correct Fig. 2 is shown below:
Publisher's note Springer Nature remains neutral with regard to jurisdictional claims in published maps and institutional affiliations.
This article is part of the Topical Collection on Erratum.

The online version of the original article can be found at https://doi.org/ 10.1007/s00259-020-04944-2

Matthew J. Roberts

m.roberts2@uq.edu.au

1 Department of Urology, Royal Brisbane and Women's Hospital, Brisbane, Australia

2 Faculty of Medicine, University of Queensland Centre for Clinical Research, Brisbane, Australia

3 Department of Urology, Redcliffe Hospital, Brisbane, Australia

4 Faculty of Medicine, The University of Queensland, Brisbane 4006, Australia
5 Department of Nuclear Medicine, Royal Brisbane and Women's Hospital, Brisbane, Australia

6 Griffith University, Brisbane, Queensland, Australia

7 Edith Cowan University, Joondalup, Western Australia

8 Department of Population Medicine, College of Medicine, QU Health, Qatar University, Doha, Qatar

9 Department of Theranostics and Nuclear Medicine, St Vincent's Hospital, Sydney, Australia

10 Faculty of Medicine, University of New South Wales, Sydney, Australia 
Fig. 2 Cox-regression adjusted analysis of progression-free survival (PFS) after radical prostatectomy (RP) for all patients according to Gleason score $\leq 3+4$ or $\geq 4+3$ (a) and within the Gleason score $\leq 3+4$ subgroup according to low (SUVmax $<8$ ) or high (SUVmax >8) 68GaPSMA-11 expression (b)

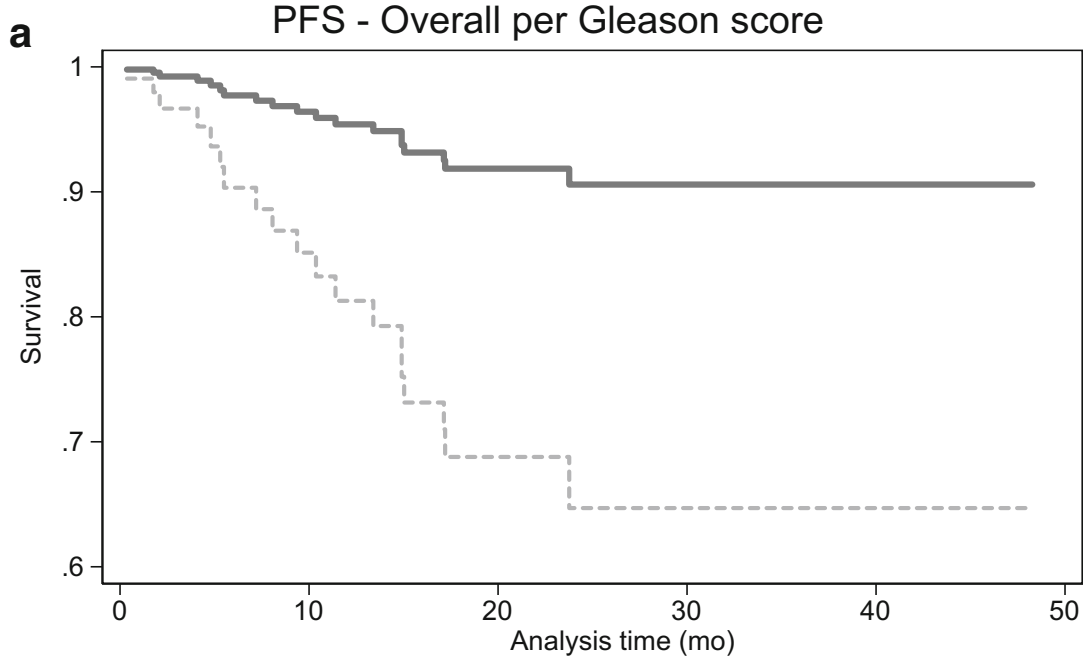

Gleason $\leq 3+4 \quad \ldots-\ldots=$ Gleason $\geq 4+3$

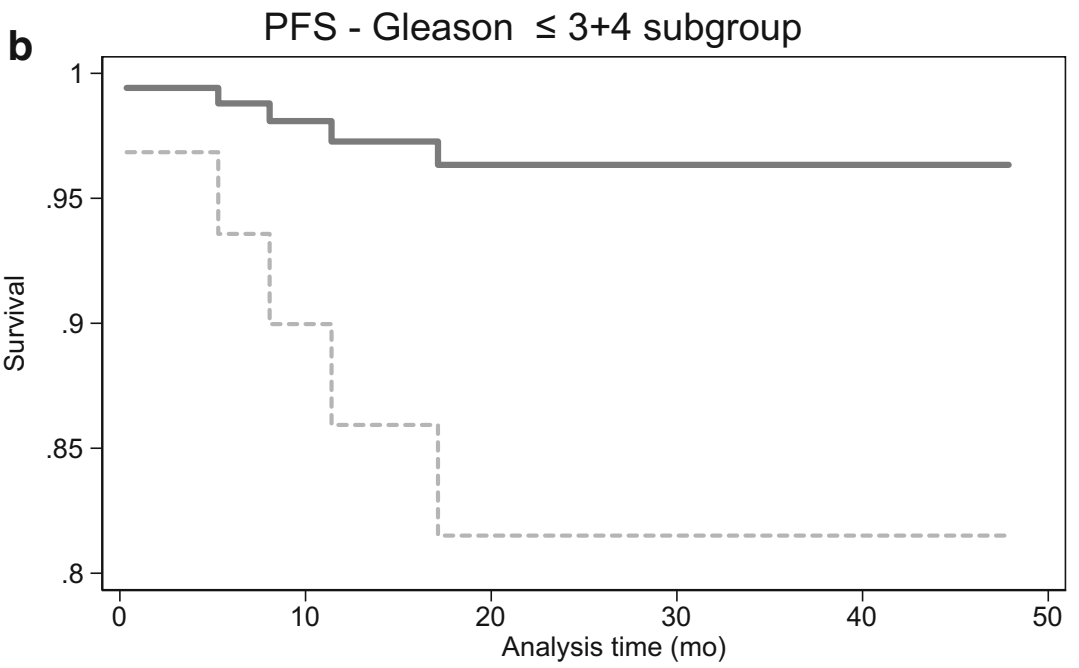

Low SUVmax - - - - - High SUVmax 